\title{
The Political Misunderstanding and Its Countermeasures on Urban planning and Construction -A Case Study of Ordos City Kang Bashi District
}

\author{
Chaowen Ji \\ School of Architecture, Linyi University \\ jichaowen@lyu.edu.cn,
}

Keywords: Kang Bashi District; urban planning; Recommendation

\begin{abstract}
In Ordos City, Kang Bashi District of Western Area, the objectives of urban planning are too big that public buildings is asked to be seeking large and novelty, Public resources are seriously wasted and other misunderstandings of "making political achievements" are also obviously. An urgent improvement of the quality of urban planning is needed of building a people-oriented ecological city.
\end{abstract}

\section{Background and Significance}

Since the reform and opening-up, with China's economic and social development, increasing in the number and scale of urban cities became an irreversible process. May 3, 2012, Li Keqiang, in China-EU partnership Summit meeting of urbanization, said: "In the future, China is committed to the promotion of scientific development, accelerating the transformation of economic development and regarding the urbanization as a major strategic modernization." However, many problems caused by the urbanization process in China related to the concern of scholars. Li Xiaoli and other scholars did a research on defects of urban planning formation, debating the solution to problem. ${ }^{[1][2]}$ In some places of our county, urban planning carried 'one emperor "one planning, local leaders became " Plan of God". The real professionals who is good at planning had become drawing tools. ${ }^{[3]}$ In some places, "urban planning" was limited by making political achievements and benefits ${ }^{[4]}$. Urban planning is getting into the misunderstanding of maximizing the benefits and political achievements, which caused by not only social and economic, cultural, technological, legal and other aspects of reasons, but also urban manager, urban planners' their own quality, and urban planning system.

Ordos City, Kang Bashi district developed rapidly since the reform and opening-up; Also considered as a famous "Ghost Town" - buildings everywhere, resident sparsely populated. It makes great sense to study the political misunderstanding of urbanization and urban planning in Ordos Kang bashi district for exploring healthy urban planning development.

\section{Ordos City, Kang Bashi District}

Kang Bashi District, Ordos City is located in southern Inner Mongolia, formerly known as Youth Hill Economic and Technological Development Zone. Inner Mongolia municipality government in December 2000 approved of the establishment. April 13, 2004, by the Inner Mongolia municipality Government's decision, it renamed Kang Bashi District. The planned control area of Kang Bashi district is $155 \mathrm{~km}^{2}$ and the planned construction area is $32 \mathrm{~km}^{2}$. The municipal infrastructure projects in Kang Bashi district has a total investment of nearly 3.6 billion yuan currently. Reaching an area of $479.6 \mathrm{hm}^{2}$.

\section{Kang Bashi District urban planning achievements Mistakes}

Planning target virtual big and unrealistic. If you follow the "checklist" your paper will conform to the requirements of the publisher and facilitate a problem-free publication process. The urban 
planning of Ordos City: "Raecent plan: In 2015, the City population is aimed at reaching about $2,400,000$ people and $80 \%$ of the level of urbanization .Also, the urban population is aimed at reaching about 1.9 million." "Kang Bashi area resident population would be 1,000,000." In 2010 Ordos City, the 6th total populations of wide survey reached 1,940,700. According to China's 2011 natural population growth rate of $4.79 \%{ }^{[5]}$, In 2015, Ordos City, the total population is about $1,987,800$ (at end of 2014 sample survey on population changes showed, resident population in Ordos City west 2,034,900); To achieve the planned population, 400,000 people are supposed to move. China's major flow trend since 2010 has been the migration to the eastern and southeastern coastal areas from the Midwest ${ }^{[6]}$. However, the Ordos City, which is located in the west of China, flowed into more than 40 million people, and it was hard to find the answer from it.

According to the statistics in 2010, resident population of Kang Bashi District was less than 30,000 . But they are supposed to reach $1,000,000$ people in planning targets for 2015. If they achieved the required planning objectives, the speed of population growth would be extremely rapidly. Even though in the reform and opening-up times of Shenzhen (population growth), it is also unable to meet the planning objectives. Kang Bashi resident population statistics also verify the virtually large planning target in 2014, "Kang Bashi District now living population is about 49549 people (including residents and Immigrants)." ${ }^{[7]}$ Comprehensive local media reported: the resident populations of Kang Bashi District was 70,000 in 2011, reaching 100,000 in 2012. Thus, the planning objectives of Kang Bashi District is seriously out of local realities.

Serious waste of public resources \& unsustainable. In Kang Bashi District, hardware build-up have been mostly achieved for urban planning objectives, it is becoming more political achievements of local government, such as $1422 \mathrm{hm}^{2}$ of green area in build-up area, $1522 \mathrm{hm}^{2}$ of green coverage area in build-up area, $41 \%$ of green rate in build-up area, $44 \%$ of green coverage rate, it was reached $32.22 \%$ of forest coverage rate, $100.09 \mathrm{~m}^{2}$ of green park area by per citizen. ${ }^{[7]}$ "Kang Bashi District in 2014 planned to plant 71720 wild apricots, 9418 Sinkiang poplars, 20,682 hybrid poplars, 145,062 Pinus sylvestris. And it is expected to complete $255 \mathrm{hm}^{2}$ of green area" and so on.

The urban construction in Kang Bashi District depends on government investment, the city is only shaped for its beautiful looking. But the lacking of urban population transformed from industrial population with industrialization, resulting that the speed of population urbanization is much more slower than the land urbanization's, also far less than the number of the resident population for planned objectives. Urban construction takes up a lot of land resources and per capita land index far exceeded national standards and China's urban average. For example, in 2014, the area of China's urban per capita green parks was 12.64. However,the the area of per capita green parks in Kang Bashi District is $100.09 \mathrm{~m}^{2}$, forming "empty City" phenomenon. The annual rainfalls in Kang Bashi District is only $170-350 \mathrm{~mm}$. It is also not easy to plant lots of arbors and broadleaves in parks, and green spaces,. Especially in Kang Bashi District whose majority of water depending on imports. It's also optimistic to keep ecological sustainability.

The Public buildings seeking large and difference, poor economical efficiency. The urban construction constructions in Kang Bashi District included a large amount of government office buildings, cultural and sports facilities. Especially cultural and sports facilities seek their peculiar images and large scales. In 2007, Ordos government invited 100 architects from the world. They designed and constructed 100 buildings, such as the Ordos Grand Theatre, which used Mongolian national headdress as model. Such as seven cultural buildings, including Erdos theatre adopts a model of Mongolian ethnic headdress, theater, concert hall, film and cultural areas and office in one of the large-scale comprehensive Theatre; the appearance of the construction area of more than $40000 \mathrm{~m}^{2}$ of the Ordos museum is a suffused with metallic luster, rounded bump of rock. (see Table 1). 
Table 1: $\quad$ the Seven Most Cultural Projects of Ordos City in Kang Bashi District

\begin{tabular}{lccc}
\hline \multicolumn{1}{c}{ Title } & $\begin{array}{c}\text { Building area } \\
{\left[\mathrm{m}^{2}\right]}\end{array}$ & $\begin{array}{c}\text { Construction area } \\
{\left[\mathrm{m}^{2}\right]}\end{array}$ & $\begin{array}{c}\text { Investment } \\
{[\text { billion yuan }]}\end{array}$ \\
\hline International Exhibition Center & 83375 & 47480 & 4 \\
Cultural Arts Center & 22540 & 42285.17 & 3.178 \\
Library & 21200 & 41350.8 & 2.77 \\
Grand Theatre & 22700 & 38406.5 & 7 \\
News Building & 16600 & 44200 & 2.9 \\
Natural History Museum & 27760 & 41227 & 5 \\
Sports Center & 90000 & 338100 & 38 \\
\hline
\end{tabular}

The political achievements of urban planning and construction in Kang Bashi District are great. But these large scales, integrated facilities are mostly idle or semi-idle states, with low utilization rates and poor economical efficiency. For instance, there are 60,000 seats of Stadium, 12,000 seats of stadium, 4000 seats of swimming pools in Ordos Sports Center. Ordos International Convention and Exhibition Center from July 2009 to June 2014, has hold more than 80 large-scale exhibitions and more than 20 international events.

\section{Recommendation}

Improve the quality of urban planning. Urban planning is the benchmark for local government to lead the urbanization, also is a blueprint for urban construction. We must correctly understand the stage characteristics of urban development. Accurately assess the objective local conditions, following the objective rules, rationally determine the scale of the city, the key and timing of construction, avoiding changing urban planning into performance engineering due to one executive's will or urbanization impulse of local governments.

To improve the quality of urban planning, there are two main aspects: First, establish a scientific planning procedures and mechanisms. Planners should be ensured to be independent and objective so that they can make scientific and rational urban planning, guaranteeing its scientificity, applicability and feasibility. Establish multi-party participation mechanisms on urban planning, including the third-party evaluation mechanism, public participation mechanisms and so on. And it should avoid relevant procedures being a mere formality. Second, the correction mechanism of urban planning. Rigid implementation of urban planning and full implementation are guarantee of the healthy development of the city. However, when a huge bias of the implementation of urban planning appeared, the government should not avoid making amendments due to the Rigid planning. It should learn from the Deming mode namely PDCA cycle (Plan, Do, Check, Action), and constantly improve urban planning, improve the quality of urban planning.

Build green conservation-oriented city. Urbanization is a symbol of human civilization and social progress, is the results of absorbing and gathering population with the industrial development and industrial clustering process. And urbanization has a big meaning to local economic development, but it had a negative effect of ecological issues. Urbanization and urban planning should respect nature and protect nature. Mostly, avoiding pollution and destroy to the environment. We should conform to the needs of social development, guide the needs of social development, construct high quality and healthy living environment for residents and guide good environmental habits to residents. We should learn from the experience of the world's urbanization and urban development, and take intensive efficiency and ecological roads.

People First. People come first then city goes by. The urbanization should be focused on residential urbanization. Residential urbanization should take appropriate survival of people living, personal development growth as a precondition to fully respect the role of market mechanism in the allocation of resources, industrial agglomeration, economic development, population migration. In order to maximize the public interest, not personal interest or less affected by the principle of 
planning intervention. Urban planning and construction for the soul to be livable, planning and construction has a suitable living space environment, harmonious social environment, ecology and quality of the natural environment and clean and efficient production environment city.

\section{Conclusion}

Urbanization with population agglomeration is the vane of social progress and economic development. Local relevant authorities and people should find out the real situations idealistically, scientifically foresight to lead urbanization and plan and construct city scientifically. We should avoid making "performance concept" become "baton" of urban planning, ensure that the healthy development of local even national urbanization and urban construction.

\section{References}

[1]Feng Huang, Xiaoli Li. Urban Construction Theory Research .2012 (32). In Chinese Http://c.wanfangdata.com.cn/Periodical-csjsllyj.aspx.2013 , 05,13

[2] Yong Wang, Guangbin Li. The return of social right. planning and management In Chinese.2009,2 (2) 56--60

[3] Xinhua Network "performance concept" became a "baton". Urban planning became a "drawing on paper" [EB/OL] In Chinese. http://news.xinhuanet.com/politics/2014-07/02/ c_1111429258.htm. 2014,07,02

[4] Xinhua Newspaper Network. "Urban planning", how can it be coerced by political achievements and benefits [EB/OL] In Chinese .http: //news.xhby.net/system/2009/09/15/010587468.shtml,2009,09 , Fifteen

[5] The Beijing News (Beijing) NBS: China's natural population growth rate is declining year by year. [EB/OL] .In Chinese. http://news.163.com/12/0818/02/895I9KKN00014AED.html.2012,08,. 18.

[6] Zhenzhen Zheng, Ge Yang. Chinese migration status and future trend. China's Social Sciences Online [In Chinese]http://news.hexun.com/2013-04-29/153668707.html.2013,05,13

[7] Window of Kangbashi--demographic situation In Chinese http://www.kbs.gov.cn/kbs2014/zjkbs_74569/rkzk/ 